\title{
Phytosulfokine stimulates cell divisions in sugar beet (Beta vulgaris L.) mesophyll protoplast cultures
}

\author{
Ewa Grzebelus • Marek Szklarczyk • Joanna Greń • \\ Katarzyna Śniegowska • Magdalena Jopek · Iwona Kacińska • \\ Katarzyna Mrożek
}

Received: 6 August 2011/Accepted: 27 December 2011/Published online: 7 January 2012

(C) The Author(s) 2012. This article is published with open access at Springerlink.com

\begin{abstract}
The aim of this work was to improve plating efficiency of sugar beet mesophyll protoplast cultures. Preliminary experiments showed that cultures of good quality, viable protoplasts were obtained in rich media based on the Kao and Michayluk formulation and with the calcium alginate as an embedding matrix. Nevertheless, in these cultures cell divisions were either not observed or very seldom confirming earlier reported recalcitrance of sugar beet protoplasts. The recalcitrant status of these cultures was reversed upon application of exogenous phytosulfokine (PSK) - a peptidyl plant growth factor. The highest effectiveness of PSK was observed at $100 \mathrm{nM}$ concentration. Plating efficiencies obtained in the presence of PSK reached approximately $20 \%$ of the total cultured cells. The stimulatory effect of phytosulfokine was observed for all tested breeding stocks of sugar beet. Our data indicate that PSK is a powerful agent able to overcome recalcitrance of plant protoplast cultures.
\end{abstract}

Keywords Sugar beet - Protoplast culture .

Phytosulfokine $\cdot$ PSK $\cdot$ Cell division

\section{Introduction}

Despite the substantial progress made over the last two decades sugar beet is still considered to be a recalcitrant species with respect to protoplast culture (Majewska-

E. Grzebelus · M. Szklarczyk ( $₫)$ · J. Greń · K. Śniegowska • M. Jopek · I. Kacińska · K. Mrożek

Department of Genetics, Plant Breeding and Seed Science, Faculty of Horticulture, University of Agriculture in Krakow, A1. 29 Listopada 54, 31-425 Krakow, Poland

e-mail: m.szklarczyk@ur.krakow.pl
Sawka and Münster 2003). Major improvements were introduced with the use of (1) $n$-propyl gallate (nPG) - a lipoxygenase inhibitor included both in the isolation and culture media (Krens et al. 1990), (2) protoplast embedding-especially in calcium alginate (Schlangstedt et al. 1992; Hall et al. 1993), (3) feeder systems exploiting nurse protoplasts or cells from suspension culture (Hall et al. 1993) and (4) stomatal guard cells or hypocotyl-derived friable callus as protoplast sources (Hall et al. 1997; Dovzhenko and Koop 2003). However, the latter two improvements involve rather complex manipulations and therefore, they are not well-suited for the routine laboratory practice. Moreover, in most reported cases responsiveness of the sugar beet protoplast culture was shown to be strictly genotype-dependent limiting its use for purposes where wider gene pool is required (Jeżdżewska et al. 1995). For these reasons the problem of sugar beet protoplast recalcitrance is still addressed in scientific efforts-both in terms of its biochemical basis and possible circumvention (Wiśniewska and Majewska-Sawka 2007, 2008). Chemical factors, which have been reported to increase plating efficiency of sugar beet protoplasts, include: (1) already mentioned $n$-propyl gallate, (2) exogenous polyamines and (3) arabinogalactan proteins. However, none of them is sufficient enough to overcome recalcitrance of sugar beet leaf protoplast culture.

In recent years peptide hormones have been recognized as important regulatory molecules in plant cells (Ryan et al. 2002, Matsubayashi 2003). One of them is phytosulphokine (PSK) isolated for the first time from asparagus mesophyll cell cultures by Matsubayashi and Sakagami (1996). PSK is a five amino acid peptide containing two posttranslationally sulfated tyrosine residues. This molecule results from cleavage of the precursor proteins. Tyrosine sulfation of the preprophytosulfokine is catalyzed 
by the tyrosylprotein sulfotransferase in the Golgi apparatus (Hanai et al. 2000). PSK is known to promote mitogenic activity-this effect was observed both in lowdensity cell suspensions and in callus cultures. It was also shown to stimulate somatic embryogenesis, tracheary element differentiation and formation of adventitious roots. Moreover, PSK is involved in density-dependent pollen germination, cellular longevity and exhibits protective effect against high night temperature (Lorbiecke et al. 2005 and ref. therein, Matsubayashi et al. 2006). Its effects were observed in plants as diverse as dicotyledons, monocotyledons and conifers.

Due to its universal character PSK is a good candidate supplement for plant in vitro cultures-similarly to widely exploited auxins, cytokinins and gibberellins. The only protoplast cultures, which have been shown to respond to PSK with enhanced proliferation activity, were derived from cell suspensions of rice (Matsubayashi et al. 1997). In this paper we report a very high positive impact of PSK on otherwise extremely recalcitrant sugar beet leaf protoplast culture.

\section{Materials and methods}

\section{Donor plants}

Six different breeding stocks of sugar beet (Beta vulgaris L.) were used as donors for protoplast isolation-male-sterile lines: S 00 1073-1, S 02 131, S 02 203, S-79-9-2 as well as male-fertile lines: $21-46-4-5$ and 24-05-1-3. These materials had doubled haploid origin and were produced through in vitro culture of unpollinated ovules in sugar beet breeding company KHBC Straszków, Poland. Protoplasts were isolated from established shoot cultures which were maintained by transferring individual shoots in 2 weeks intervals on fresh BCM medium-MS including vitamins (Murashige and Skoog 1962) supplemented with $0.3 \mathrm{mg} \mathrm{l}^{-1} N^{6}$-benzylaminopurine (BAP), $0.1 \mathrm{mg} \mathrm{l}^{-1} \alpha$-naphthaleneacetic acid (NAA), $0.3 \mathrm{mg} \mathrm{l}^{-1}$ thiamin- $\mathrm{HCl}, 3 \%$ (w/v) sucrose and $0.7 \%$ (w/v) agar (Plant Propagation Lab Agar, Biocorp), $\mathrm{pH}=5.8$. To prevent endogenous bacterial contaminations often found in sugar beet tissue cultures cefotaxime was filter-sterilized $(0.22 \mu \mathrm{m}$, Millipore $)$ to the autoclaved medium to the final concentration of $200 \mathrm{mg} \mathrm{l}^{-1}$. Shoot cultures were grown in a climate room at $26 \pm 2{ }^{\circ} \mathrm{C}$, under light intensity of $55 \mu \mathrm{mol} \mathrm{m} \mathrm{m}^{-2} \mathrm{~s}^{-1}$ with 16 -h photoperiod.

Protoplast isolation and purification

Protoplasts were isolated from leaves of the 2 week-old shoot cultures (Fig. 1a). 5-10 leaves (approx. 1 g) were cut into fine pieces in a $9 \mathrm{~cm}$ glass Petri dish containing $8 \mathrm{ml}$ of the plasmolysis solution (0.5 M mannitol) and incubated for $1 \mathrm{~h}$ at $26^{\circ} \mathrm{C}$ in the dark. Then the tissue was macerated in the enzyme mixture containing of $1 \%(\mathrm{w} / \mathrm{v})$ cellulase Onozuka R-10 (Duchefa), 1.5\% (w/v) macerozyme R-10 (Serva), $30 \mathrm{mM}$ 2-(N-morpholino) ethanesulfonic acid (MES, Sigma) and 0.45 M D-sorbitol (Sigma) in cell protoplast wash (CPW) solution (Frearson et al. 1973). Maceration was performed overnight at $26^{\circ} \mathrm{C}$ with continuous gentle shaking (30 rpm). Quality of the released protoplasts was examined under inverted microscope (Axiovert S100, Zeiss). Subsequently, the suspension was passed through a $80 \mu \mathrm{m}$ nylon sieve (Millipore) in order to remove undigested tissue and then centrifuged at 1,000 rpm for $5 \mathrm{~min}$. The pellet was resuspended in $8 \mathrm{ml}$ of $0.5 \mathrm{M}$ sucrose, $1 \mathrm{mM}$ MES and overlaid with $2 \mathrm{ml}$ of W5 solution (Menczel et al. 1981). After centrifugation at 1,200 rpm for 10 min pure and viable protoplasts were concentrated on the interphase between the two solutions. Collected with a Pasteur pipette protoplasts were then washed twice: first in $10 \mathrm{ml}$ of the W5 solution and then in $10 \mathrm{ml}$ of the culture medium (see section Protoplast culture). After each wash the protoplasts were spun down at $1,000 \mathrm{rpm}$ for $5 \mathrm{~min}$.

\section{Protoplast embedding}

After purification the protoplasts were suspended in approx. $1 \mathrm{ml}$ of the culture medium and their yield was determined using a Fuchs-Rosenthal hemocytometer. After that cell density was brought to $8 \times 10^{5}$ per $\mathrm{ml}$. Two systems of protoplast immobilization were tested: embedding in thin layers of calcium alginate (Ca-alginate) and embedding in agarose beads. In the former method a modified protocol of Damm et al. (1989) was used. First, equal volumes of the protoplast suspension and an autoclaved solution of $2.8 \%$ alginic acid sodium salt (Sigma), $0.4 \mathrm{M}$ mannitol were mixed carefully. Subsequently aliquots (approx. $300 \mu \mathrm{l}$ ) of the protoplasts/alginate mixture were spread as thin layers in $6 \mathrm{~cm}$ Petri dishes on $1 \%(\mathrm{w} / \mathrm{v})$ agar (Biocorp) containing $20 \mathrm{mM} \mathrm{CaCl}_{2}$ and $0.4 \mathrm{M}$ mannitol. After $1 \mathrm{~h}$ incubation at room temperature solidified alginate-protoplast layers were transferred into $6 \mathrm{~cm}$ Petri dishes containing $4 \mathrm{ml}$ of the culture medium. In the second immobilization system two types of low-gelling temperature agarose were used. These were filter-sterilized solutions of $0.6 \%$ (w/v) agarose type VII (Sigma) and $1.2 \%$ SeaPlaque agarose (Duchefa) in the culture medium. Equal volumes of the protoplast suspension and agarose solution (of approx. $40^{\circ} \mathrm{C}$ ) were mixed and seven $50 \mu$ l-aliquots of the resulting mixture were dropped onto the bottom of a $6 \mathrm{~cm}$ Petri dish. After agarose solidification $4 \mathrm{ml}$ of the culture medium was added. In all immobilization methods the final density of the embedded protoplasts was $4 \times 10^{5}$ per ml. 

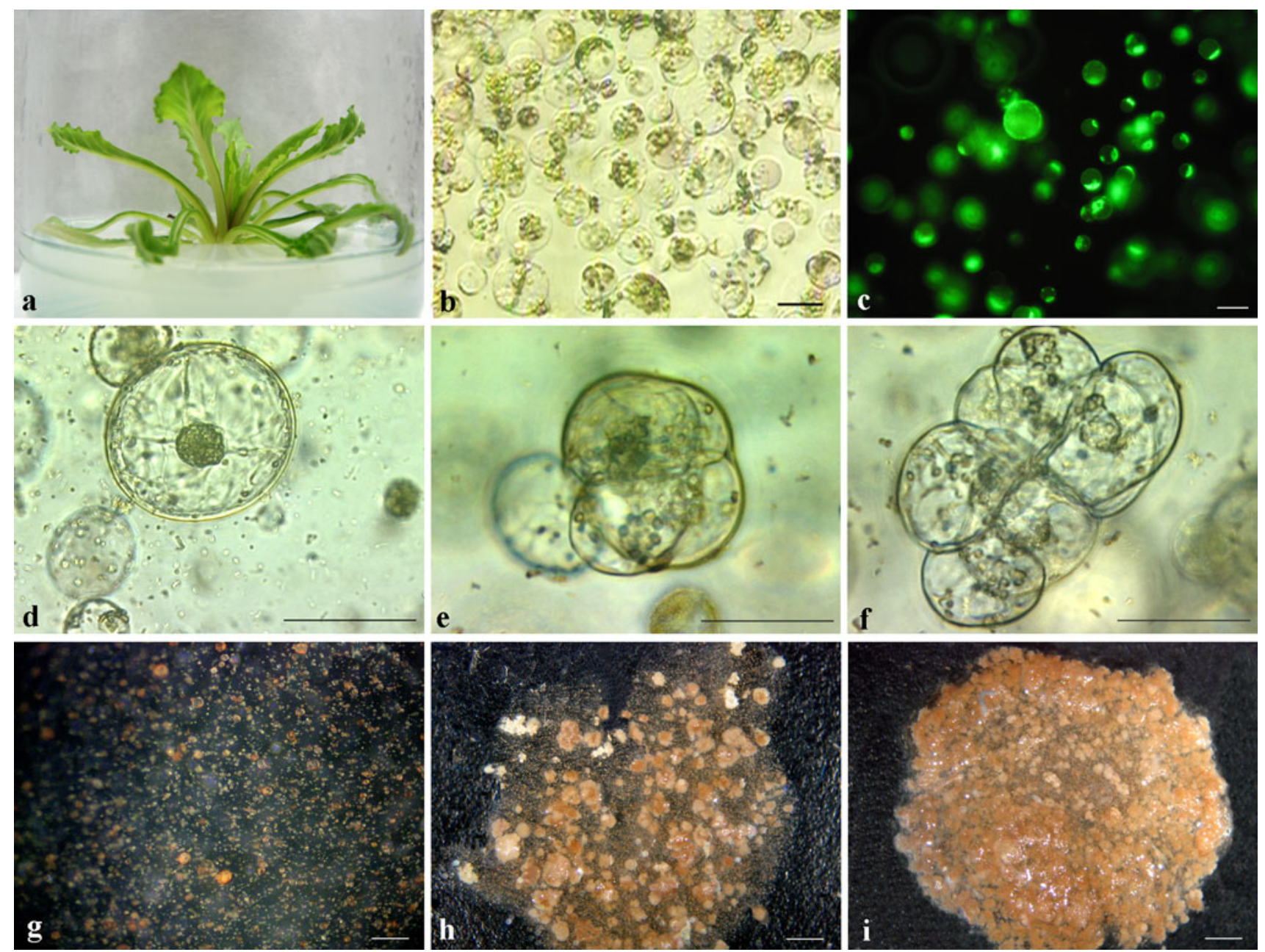

Fig. 1 Different stages of sugar beet leaf protoplast isolation and culture. a Donor plant from 2 week-old shoot culture. b Freshly isolated leaf protoplasts. c Leaf protoplasts stained with fluorescein diacetate (FDA). $\mathbf{d}, \mathbf{e}, \mathbf{f} 7$-day cultures grown in calcium alginate and medium 2B with 0,10 and $100 \mathrm{nM}$ phytosulfokine (PSK), respectively. $\mathbf{g}, \mathbf{h}, \mathbf{i}$ Protoplast-derived macrocalli in 2-month cultures grown in calcium alginate and medium 2B with 0,10 and $100 \mathrm{nM}$ PSK, respectively. Scale bars represent either $50 \mu \mathrm{m}(\mathbf{b}-\mathbf{f})$ or $0.5 \mathrm{~cm}(\mathbf{g}-\mathbf{i})$

\section{Protoplast culture}

In preliminary experiments the embedded protoplasts were cultured in the three different liquid culture media. Medium 1B contained: macro-, microelements and vitamins according to MS (Murashige and Skoog 1962), 12\% (w/v) sucrose, $0.5 \mathrm{mg} \mathrm{l}^{-1}$ BAP and $1 \mathrm{mg} \mathrm{l}^{-1}$ NAA. Medium 2B contained: macro-, microelements and organic acids according to $\mathrm{KM}$ ( $\mathrm{KaO}$ and Michayluk 1975), vitamins as in B5 (Gamborg et al. 1968), 7.4\% glucose, $250 \mathrm{mg} \mathrm{l}^{-1}$ casein enzymatic hydrolysate (Sigma), $8 \mathrm{mg} \mathrm{l}^{-1}$ putrescine (Sigma), $0.1 \mathrm{mg} \mathrm{l}^{-1} 2,4$ dichlorophenoxyacetic acid (2,4-D) and $0.2 \mathrm{mg}^{-1}$ zeatin. Medium 3B was composed as 2B with addition of $\mathrm{KM}$ vitamins, $2 \%(\mathrm{v} / \mathrm{v})$ coconut water and $15 \%(\mathrm{w} / \mathrm{v})$ sucrose. In further experiments media $2 \mathrm{~B}$ and $3 \mathrm{~B}$ were supplemented with either 10,100 or $1,000 \mathrm{nM}$ phytosulfokine- $\alpha$ (PSK). PSK was synthesized by Peptide Institute, Inc. (Osaka, Japan). All media contained cefotaxime at concentration of $200 \mathrm{mg} \mathrm{l}^{-1}$.

Protoplast cultures were incubated at $26^{\circ} \mathrm{C}$ in the dark until callus macrocolonies were formed (approx. 2 months). After each 10 days of culture the medium was replaced with its fresh portion in order to remove toxin substances produced by the cells.

All solutions and media used for protoplasts isolation, washing and culture contained $10 \mu \mathrm{M} n$-propyl gallate (nPG, Sigma) as an antioxidant. The culture media (1B, 2B, 3B) and enzyme solution were adjusted to $\mathrm{pH} 5.6$ and filter-sterilized $(0.22 \mu \mathrm{m}$, Millipore). All other solutions and culture media were adjusted to $\mathrm{pH} 5.8$ and autoclaved (21 $\left.\min , 121^{\circ} \mathrm{C}, 0.1 \mathrm{MPa}\right)$. 
Microscopic observations and data analysis

Protoplast viability was assessed by staining with fluorescein diacetate (FDA) according to the protocol of Anthony et al. (1999). For this purpose $60 \mu \mathrm{l}$ of $0.3 \%$ FDA acetone stock was added to $4 \mathrm{ml}$ of the culture medium to yield the FDA working solution. $100 \mu$ of this solution was added to a Petri dish with the protoplast culture. Apple-green fluorescence of viable cells was examined under Zeiss Axiovert S100 microscope equipped with the appropriate filter set $\left(\lambda_{\mathrm{Ex}}=485, \lambda_{\mathrm{Em}}=515 \mathrm{~nm}\right)$ (Fig. 1c). Plating efficiency was expressed as the number of divided cells per total number of plated protoplasts multiplied by 100 .

Data were collected in three independent experiments. Each treatment was set up in three replicates. For a single Petri dish both viability and plating efficiency counts were carried out in five microscopic fields with 100-400 cells. The mean values and standard errors were calculated. The overall effect of treatments was assessed using analysis of variance (ANOVA) with Tukey's honestly significant difference (HSD) test. Significant differences were expressed at $P \leq 0.05$. The computations were performed using Statistica software ver. 8 (StatSoft. Inc.).

\section{Results}

To improve plating efficiency of sugar beet protoplast culture, the following parameters were assessed with respect to their impact on protoplast viability and colony formation: (1) type of protoplast embedding agent, (2) type of culture medium and (3) concentration of phytosulfokine (PSK) in the culture medium.

Protoplasts were efficiently released from the leaf tissue after $14-16 \mathrm{~h}$ of incubation in the enzyme solution. Protoplast yields ranged from $2.3 \pm 0.5 \times 10^{6}$ per $\mathrm{g}$ fresh weight (FW) for line S 02131 to $2.8 \pm 0.9 \times 10^{6}$ for line S 02 203. Freshly isolated protoplasts were spherical in shape, varied in size and contained numerous differentially oriented chloroplasts (Fig. 1b).

Effect of embedding matrices and culture media on protoplast development

In these experiments protoplasts were isolated from three male-sterile lines: S 00 1073-1, S 02131 and S 02203. These breeding stocks as well as different immobilization agents and culture media were examined with respect to their effect on protoplast viability and division potential.

Protoplast viability in the first hour of culture was relatively low and varied from $38 \%$ for line S 00 1073-1 to 49\% for line S 02203 (Table 1). On the next day of culture only a slight decrease in cell viability was observed while
Table 1 Viability (\%) of protoplasts isolated from three male-sterile breeding stocks and immobilized in three different embedding matrices

\begin{tabular}{llll}
\hline & \multicolumn{3}{l}{ Age of culture $(\mathrm{h})$} \\
\cline { 2 - 4 } & 1 & 24 & 48 \\
\hline Donor stock & & & \\
S 00 1073-1 & $38.3 \pm 6.0$ & $37.8 \pm 5.0$ & $29.1 \pm 3.8$ \\
S 02 131 & $45.7 \pm 4.7$ & $42.0 \pm 3.8$ & $34.2 \pm 4.8$ \\
S 02 203 & $48.7 \pm 4.3$ & $46.7 \pm 3.3$ & $38.0 \pm 4.2$ \\
Embedding matrix & & & \\
Ca-alginate & $46.7 \pm 6.3$ & $44.1 \pm 5.5$ & $38.2 \pm 5.5$ \\
Agarose type VII & $45.7 \pm 4.6$ & $42.0 \pm 3.9$ & $29.1 \pm 3.5$ \\
SeaPlaque agarose & $40.3 \pm 4.6$ & $40.3 \pm 2.9$ & $33.9 \pm 3.4$ \\
\hline
\end{tabular}

Data represent means \pm standard errors from three independent experiments (each with three replicates)

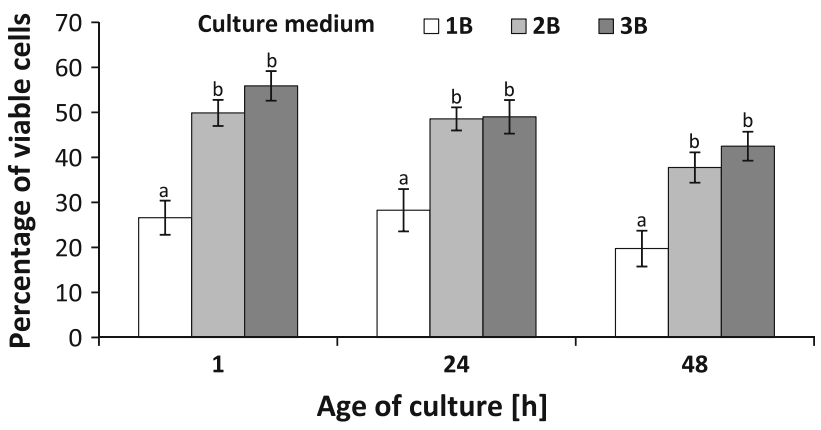

Fig. 2 Viability of protoplasts cultured in three different media. Bars represent means \pm SE obtained for three breeding stocks and three embedding matrices. Means denoted with different letters are significantly different $(P \leq 0.05)$

on the second day its value was approximately $10 \%$ lower than the one recorded immediately after isolation. In general, no significant differences were observed in viability of protoplasts isolated from different breeding stocks. Similarly, immobilization of protoplasts in Ca-alginate, agarose type VII as well as in SeaPlaque agarose resulted in comparable values of protoplast viability (Table 1). Despite the fact that in the first, 24th, and 48th hour of culture the highest viability was observed for the cells embedded in Ca-alginate it appeared to be not statistically significant. Conversely, the protoplast viability was clearly dependent on the applied culture medium (Fig. 2). More viable cells were observed in rich mineral-organic media 2B and 3B which were based on the Kao and Mychayluk formula. Medium 1B based on the Murashige and Skoog recipe resulted in approximately half-reduced cell viability. After 5 days of culture only protoplasts embedded in $\mathrm{Ca}$ alginate became larger and changed their shape from circular to elliptical indicating reconstruction of the cell wall. At that time the cells exhibited densely organized 
cytoplasm and most of their chloroplasts were no longer visible. First cell divisions were observed sporadically after approximately 7 days of culture-but only for protoplasts isolated from line S 02 203, embedded in Ca-alginate and cultured on medium 2B. Further development of these cultures was arrested after next two or three cell divisions.

Response of protoplast cultures to phytosulfokine (PSK)

In these experiments protoplasts isolated from line $\mathrm{S} 02$ 203 were embedded in Ca-alginate layers and cultured in media $2 \mathrm{~B}$ and $3 \mathrm{~B}$ supplemented with either 10,100 or $1,000 \mathrm{nM}$ phytosulfokine. In parallel, controls without added PSK were also cultured. Neither the PSK concentration nor the type of culture medium influenced protoplast viability-this parameter was also relatively stable in subsequent points of evaluation (Table 2). After 7 days of culture first cell divisions were observed only in the presence of PSK (Fig. 3). When PSK was applied in $10 \mathrm{nM}$ concentration only $1 \%$ of dividing cells was observed while in the presence of $100 \mathrm{nM}$ PSK plating efficiency was about fivefold higher. The stronger effect of $100 \mathrm{nM}$ PSK was also confirmed in the 14th and 21st day of culture-the observed values of plating efficiency reached 13 and $19 \%$, respectively. Upon increase to $1,000 \mathrm{nM}$ concentration further stimulation of cell divisions was not observed-this concentration of PSK was approximately as effective as $10 \mathrm{nM}$. As a result of the phytosulfokine application the protoplast-derived microcolonies were formed (Fig. 1d-f). After 6 weeks of culture in the Caalginate layers callus macrocolonies were clearly visible with the naked eye. At that time it also became apparent that the higher PSK concentration resulted in a faster growth of microcalli (Fig. 1g-i). There were no significant differences in plating efficiency between the two applied culture media (data not shown).

Table 2 Viability (\%) of protoplasts isolated from line S 02203 , embedded in Ca-alginate and cultured in two media supplemented with different concentrations of phytosulfokine (PSK)

\begin{tabular}{lclll}
\hline $\begin{array}{l}\text { Culture } \\
\text { medium }\end{array}$ & $\begin{array}{l}\text { PSK } \\
\text { concentration } \\
(\mathrm{nM})\end{array}$ & \multicolumn{4}{l}{ Age of culture (h) } \\
\cline { 3 - 5 } \cline { 3 - 5 } & 0 & $64.4 \pm 4.7$ & $62.0 \pm 1.7$ & $58.2 \pm 1.3$ \\
\hline B & 10 & $65.8 \pm 2.4$ & $61.0 \pm 1.9$ & $58.0 \pm 0.6$ \\
& 100 & $68.3 \pm 1.3$ & $64.0 \pm 2.7$ & $62.4 \pm 2.4$ \\
& 0 & $66.6 \pm 4.0$ & $60.0 \pm 7.1$ & $60.7 \pm 3.3$ \\
3B & 10 & $64.1 \pm 5.4$ & $58.1 \pm 3.2$ & $60.8 \pm 4.6$ \\
& 100 & $65.5 \pm 4.4$ & $64.5 \pm 3.4$ & $61.8 \pm 4.4$ \\
\hline
\end{tabular}

Data represent means \pm standard errors from three independent experiments (each with three replicates)

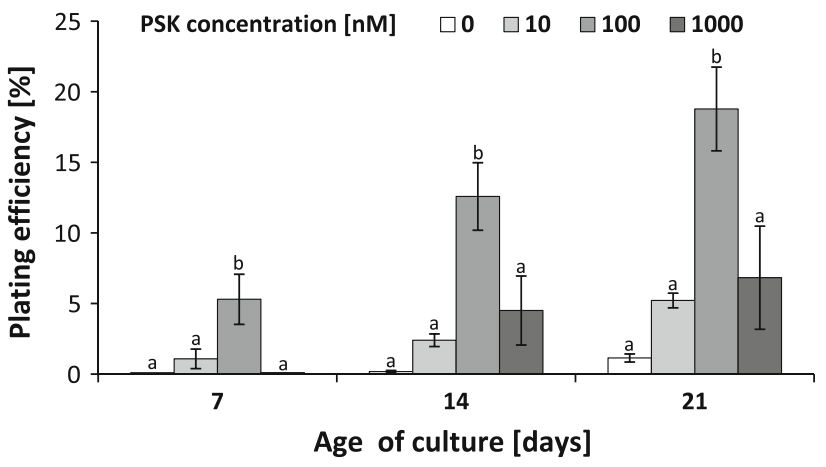

Fig. 3 Plating efficiency of protoplast cultures with different concentrations of phytosulfokine (PSK). The protoplasts were isolated from S 02203 plants and embedded in Ca-alginate. Bars represent means \pm SE obtained for two culture media ( $2 \mathrm{~B}$ and $3 \mathrm{~B})$. Means denoted with different letters are significantly different $(P \leq 0.05)$

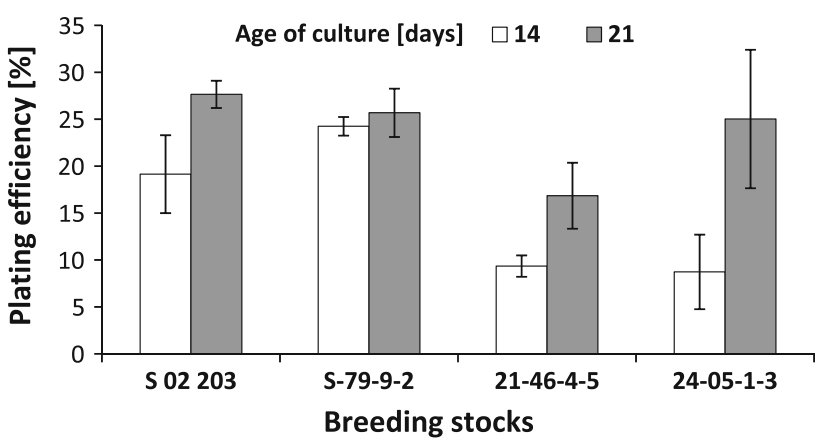

Fig. 4 Plating efficiency of protoplast cultures obtained for different sugar beet breeding stocks. The protoplasts were embedded in Caalginate and cultured in medium 2B supplemented with $100 \mathrm{nM}$ phytosulfokine (PSK). Bars represent means \pm SE

\section{Genotype dependence of PSK action}

For the purpose of this investigation mesophyll protoplasts were isolated from the two male-sterile (S 02 203, S-79-92) and two male-fertile (21-46-4-5, 24-05-1-3) lines, immobilized in the Ca-alginate layers and cultured in $2 \mathrm{~B}$ medium supplemented with $100 \mathrm{nM}$ PSK. After 2 weeks of culture plating efficiency varied from 9 (line 24-05-1-3) to $24 \%$ (line S 79-9-2, Fig. 4). 1 week later number of microcolonies increased $(P<0.05)$ and ranged from $17 \%$ for line 21-46-4-5 to $28 \%$ for line S 02 203. 2 weeks after protoplast isolation more cell colonies were observed in cultures derived from the male-sterile breeding stocks than in cultures obtained from the fertile lines $(P<0.05)$. After 3 weeks of culture the observed plating efficiency was similar for all studied breeding stocks. These data may indicate that protoplasts isolated from the male-sterile material responded faster to phytosulfokine applicationhowever, it cannot be excluded that this variation is caused by other genotypic differences. 


\section{Discussion}

Plant protoplasts have a range of biotechonological applications including somatic hybridization, somatic cybridization and gene transfer by means of either chemical treatment, microinjection or electroporation. They have also been used for organellar transplantation-in most cases uptake of chloroplasts and nuclei was reported (reviewed in Razdan 2003). The necessary prerequisite for these applications is an ability of plant protoplasts to reconstitute their cell wall and undergo mitotic divisions which results in callus formation and eventually shoot regeneration (Davey et al. 2005a). The problem is that for many species this developmental program is hard to achieve. Such recalcitrance of plant in vitro cultures is a widely known phenomenon-its importance was recognized from the very beginning of this research field (Benson 2000). With respect to protoplast cultures recalcitrance was noted for most monocotyledons, perennial woody species and legumes (Papadakis and Roubelakis-Angelakis 2002; Davey et al. 2010). This list can be extended to include sugar beet as well, at least with respect to protoplasts of mesophyll origin (Hall et al. 1993, MajewskaSawka and Münster 2003). Obviously, such limitation affects utilization of plant protoplasts for the above-mentioned very potent downstream applications. As a consequence successful use of plant protoplast cultures has been limited to well-responsive species, mainly from families Solanaceae and Brassicaceae (Davey et al. 2005a). Accordingly, so far most reports on sugar beet protoplasts have been dedicated to optimization of culture conditions and hence reports on successful (ended up with regeneration of the modified plants) biotechnological utilization of these cultures are hardly existing.

An early improvement on the way to overcome protoplast recalcitrance was to exploit actively dividing cultured cells for protoplast isolation. Although very powerful this invention has an apparent limitation-it requires prior establishment of a suspension culture, a process which takes months and itself for many plant species is far from a routine (Mustafa et al. 2011). This approach was successfully used also in case of sugar beet allowing to reach plating efficiency of about $40 \%$ (Majewska-Sawka et al. 1994, 1997). For this species two alternative protoplast sources were devised. Hall et al. (1996, 1997) reported that sugar beet stomatal guard cells exhibited totipotency and provided protoplasts for which the mean plating efficiency of the best responsive accession reached almost $22 \%$. Similar plating efficiencies were obtained by Dovzhenko and Koop (2003) with protoplasts isolated from friable regenerable callus. Both approaches proved to be very efficient-however, the former was not reproduced by other groups (Dovzhenko and Koop 2003) and the latter needs an additional investment in friable callus production which according to our experience is very difficult for some genotypes (data not shown). Here presented experiments deal exclusively with leaf protoplasts which in case of sugar beet are regarded as extremely recalcitrant. For this material reported plating efficiency ranged from 0.04 to $1.2 \%$ (Majewska-Sawka and Münster 2003). On the other hand mesophyll exhibits some important advantages as a donor tissue-it is easily available, does not require prior callus or suspension culture and its dedicated isolation protocols are relatively straightforward. Therefore, the use of leaf material would be especially desirable for applications in which large quantities of high quality protoplasts are required e.g. for fusion purposes.

Another very common way to overcome protoplast recalcitrance is to use cell culture supplements e.g. nonionic surfactants or artificial oxygen carriers which enhance physiological status of the cultured cells. Such factors are able to increase plating efficiencies even a fewfold (Davey et al. 2005b). In this report we show beneficiary effect of phytosulfokine (PSK) which represents a new class of supplements - the peptide growth factors. It is demonstrated that application of exogenous PSK is able to reverse the recalcitrant behavior of in vitro cultured cells. For the investigated here sugar beet mesophyll protoplasts the effect of PSK application was much more pronounced than caused by any other earlier studied culture supplement. We observed about 20-fold increase of plating efficiency over control lacking PSK which brings this parameter to the level observed by the authors who used the above-referenced alternative donor materials-suspension cultures, epidermis and callus. Phytosulfokine was not only launching proliferation activity-it was also essential for its maintenance. In no PSK controls even if cell divisions occurred they were soon arrested and as a result callus formation was not observed. Out of the three analyzed PSK concentrations, $100 \mathrm{nM}$ exhibited the highest activity which was within the range observed in other in vitro systems (Matsubayashi and Sakagami 1996; Hanai et al. 2000) and indicated that in sugar beet protoplast culture one of the universal pathways of PSK action was initiated. All these data also suggest that recalcitrance may be associated with insufficient production of phytosulphokine in in vitro conditions. Obviously, this hypothesis will need biochemical verification, it will also be interesting to trace expression of PSK precursor protein(s) through subsequent stages of the protoplast culture.

Except PSK other parameters of our sugar beet protoplast cultures resembled those brought by the previous reports (see above). We compared three different embedding matrices and showed superiority of the thin alginate layers. This effect may be due to the fact that agarose (1) forming thicker layers than alginate hindered diffusion 
between cells and medium or (2) contained impurities affecting proper protoplast development. It is also possible that sugar beet mesophyll protoplasts are to some extent heat-sensitive. Our experience confirms beneficiary effect of $n$-propyl gallate (nPG) although contrary to other reports we used it in concentration of 10 instead of $100 \mu \mathrm{M}$.

It seems that reasons for recalcitrance of protoplast cultures may be at least twofold. Firstly, they may be related to the stress exerted upon plant cells during protoplast isolation and subsequent culture. For example Papadakis and Roubelakis-Angelakis (2002) point at active oxygen species and oxidative stress as factors affecting regeneration potential of protoplasts. Secondly, recalcitrance may result from lack of developmental signals which are present when plants are in toto. The above categorization gains its support from nature of factors which help to overcome protoplast recalcitrance. For example, $n$ propyl gallate (nPG) seems to target the first category of phenomena through its antioxidant activity (Saleem and Cutler 1987; Krens et al. 1994). In turn, the stimulating effect of nurse cells results from the chemical signals they emit to cultured protoplasts (Hall et al. 1993, Davey et al. 2005b). It is obvious that phytosulfokine also falls into the second category of factors and once its action was even referred to as chemical nursing (Matsubayashi et al. 2004). As such PSK exhibits a few important advantages over classical nursing - (1) it is easily applicated — when using it the parallel culture of nurse cells is not required, (2) it is a defined compound, (3) its level can be precisely controlled and (4) it is a universal signal molecule suggesting that its utilization may help to overcome protoplast recalcitrance in other crops of vital economic importance like e.g. cereals. Here presented data show that in case of sugar beet mesophyll protoplasts phytosulfokine is able to boost plating efficiency of their culture to the level sufficient for downstream applications. The effect of PSK was observed for all studied sugar beet accessions although protoplast cultures obtained from the male-sterile lines responded faster to its application. The male-sterile and male-fertile accessions differ with respect to the carried cytoplasmthe former are S- and the latter N-cytoplasmic. Cytoplasmic influence on plant material in vitro performance would not be surprising as it was earlier noted for wheat, barley, maize, potato, Medicago and Brassica (Henry et al. 1994).

Acknowledgments The research was funded by the Polish Ministry of Science and Higher Education, grant no. PBZ-MNiSW-2/3/2006/ 35 awarded to MS. The authors thank to Mr. Mirosław Łakomy and Mr. Adam Sitarski from KHBC Straszków for providing the plant material for analysis.

Open Access This article is distributed under the terms of the Creative Commons Attribution Noncommercial License which permits any noncommercial use, distribution, and reproduction in any medium, provided the original author(s) and source are credited.

\section{References}

Anthony P, Otoni W, Power JB, Lowe TC, Davey MR (1999) Protoplast isolation, culture and plant regeneration from Passiflora. In: Hall RD (ed) Methods in molecular biology: plant cell culture protocols. Humana Press, Totowa, pp 169-179

Benson EE (2000) In vitro plant recalcitrance: an introduction. In Vitro Cell Dev Biol-Plant 36:141-148

Damm B, Schmidt R, Willmitzer L (1989) Efficient transformation of Arabidopsis thaliana using direct gene transfer to protoplasts. Mol Gen Genet 217:6-12

Davey MR, Anthony P, Power JB, Lowe KC (2005a) Plant protoplasts: status and biotechnological perspectives. Biotechnol Adv 23:131-171

Davey MR, Anthony P, Power JB, Lowe KC (2005b) Plant protoplast technology: current status. Acta Physiol Plant 27:117-129

Davey MR, Anthony P, Patel D, Power JB (2010) Plant cell culture: essential methods. In: Davey MR, Anthony P (eds) Plant protoplasts: isolation, culture and plant regeneration. WileyBlackwell, London, pp 153-173

Dovzhenko A, Koop HU (2003) Sugar beet (Beta vulgaris L.): shoot regeneration from callus and callus protoplasts. Planta 217:374-381

Frearson EM, Power JB, Cocking EC (1973) The isolation, culture, and regeneration of Petunia leaf protoplasts. Dev Biol 33:130-137

Gamborg OL, Miller RA, Ojima K (1968) Nutrient requirements of suspension cultures of soybean root cells. Exp Cell Res 50:151-158

Hall RD, Pedersen Ch, Krens FA (1993) Improvement of protoplast culture protocols for Beta vulgaris L. (sugar beet). Plant Cell Rep 12:339-342

Hall RD, Riksen-Bruinsma T, Weyens C, Lefèbvre M, Dunwell JM, Krens FA (1996) Stomatal guard cells are totipotent. Plant Physiol 112:889-892

Hall RD, Riksen-Bruinsma T, Weyens G, Lefèbvre M, Dunwell JM, van Tunen A, Krens FA (1997) Sugar beet guard cell protoplasts demonstrate a remarkable capacity for cell division enabling applications in stomatal physiology and molecular breeding. J Exp Bot 28:255-263

Hanai H, Matsuno T, Yamamoto M, Matsubayashi Y, Kobayashi T, Kamada H, Sakagami Y (2000) A secreted peptide growth factor, phytosulfokine, acting as a stimulatory factor of carrot somatic embryo formation. Plant Cell Physiol 41:27-32

Henry Y, Vain P, De Buyser J (1994) Genetic analysis of in vitro plant tissue culture responses and regeneration capacities. Euphytica 79:45-58

Jażdżewska E, Niklas A, Majewska-Sawka A (1995) Progress towards sugar beet improvement through somatic hybridization. Acta Soc Bot Pol 64:341-347

Kao KN, Michayluk MR (1975) Nutritional requirements for growth of Vicia hajastana cells and protoplasts at a very low population density in liquid media. Planta 126:105-110

Krens FA, Jamar D, Rouwendal GJA, Hall RD (1990) Transfer of cytoplasm from new Beta CMS sources to sugar beet by asymmetric fusion. 1. Shoot regeneration from mesophyll protoplasts and characterization of regenerated plants. Theor Appl Genet 79:390-396

Krens FA, Jamar D, Keizer LCP, Hall RD (1994) The effect of $\mathrm{n}$-propyl gallate on the formation of ethylene during protoplast isolation in sugar beet (Beta vulgaris L.). J Exp Bot 45:1899-1901

Lorbiecke R, Steffens M, Tomm JM, Scholten S, Von Wiegen P, Kranz E, Wienand U, Sauter M (2005) Phytosulphokine gene regulation during maize (Zea mays L.) reproduction. J Exp Bot 56:1805-1819 
Majewska-Sawka A, Münster A (2003) Cell-wall antigens in mesophyll cells and mesophyll-derived protoplasts of sugar beet: possible implication in protoplast recalcitrance? Plant Cell Rep 21:946-954

Majewska-Sawka A, Nakashima H, Mori K (1994) Isolation and culture of suspension-derived protoplasts of Beta vulgaris L. Biol Plant 36:9-13

Majewska-Sawka A, Niklas A, Jażdżewska E (1997) The effect of polyamines on the development of sugar beet protoplasts. Biol Plant 39:561-567

Matsubayashi Y (2003) Ligand-receptor pairs in plant peptide signaling. J Cell Sci 116:3863-3870

Matsubayashi Y, Sakagami Y (1996) Phytosulfokine, sulfated peptides that induce the proliferation of single mesophyll cells of Asparagus officinalis L. Proc Natl Acad Sci USA 93:7623-7627

Matsubayashi Y, Takagi L, Sakagami Y (1997) Phytosulfokine- $\alpha$, a sulfated pentapeptide, stimulates the proliferation of rice cells by means of specific high-and low-affinity binding sites. Proc Natl Acad Sci USA 94:13357-13362

Matsubayashi Y, Goto T, Sakagami Y (2004) Chemical nursing: phytosulfokine improves genetic transformation efficiency by promoting the proliferation of surviving cells on selective media. Plant Cell Rep 23:155-158

Matsubayashi Y, Ogawa M, Kihara H, Niwa M, Sakagami Y (2006) Disruption and overexpression of Arabidopsis phytosulfokine receptor gene affects cellular longevity and potential for growth. Plant Physiol 142:45-53
Menczel L, Nagy F, Kiss Z, Maliga P (1981) Streptomycin resistant and sensitive somatic hybrids of Nicotiana tabacum + Nicotiana knightiana: correlation of resistance to $N$. tabacum plastids. Theor Appl Genet 70:590-594

Murashige T, Skoog F (1962) A revised medium for rapid growth and bioassays with tobacco tissue culture. Physiol Plant 18:100-127

Mustafa NR, de Winter W, van Iren F, Verpoorte R (2011) Initiation, growth and cryopreservation of plant cell suspension cultures. Nat Protoc 6:715-742

Papadakis AK, Roubelakis-Angelakis KA (2002) Oxidative stress could be responsible for the recalcitrance of plant protoplasts. Plant Physiol Biochem 40:549-559

Razdan MK (2003) Introduction to plant tissue culture. Science Publishers, Enfield

Ryan CA, Pearce G, Scheer J, Moura DS (2002) Polypeptide hormones. Plant Cell (Suppl) 14:S251-S264

Saleem M, Cutler AJ (1987) Stabilizing corn leaf protoplasts with n-propyl gallate. J Plant Physiol 128:479-484

Schlangstedt M, Hermans B, Zoglauer K, Schieder O (1992) Culture of sugar beet protoplasts in alginate-callus formation and root organogenesis. J Plant Physiol 140:339-344

Wiśniewska E, Majewska-Sawka A (2007) Arabinogalactan-proteins stimulate the organogenesis of guard cell protoplasts-derived callus in sugar beet. Plant Cell Rep 26:1457-1467

Wiśniewska E, Majewska-Sawka A (2008) The differences in cell wall composition in leaves and regenerating protoplasts of Beta vulgaris and Nicotiana tabacum. Biol Plant 52:634-641 